\title{
PAEDIATRICS
}

\section{Nutrition and respiratory health in children in six Central and Eastern European countries}

\section{T Antova, S Pattenden, B Nikiforov, G S Leonardi, B Boeva, T Fletcher, P Rudnai, H Slachtova, C Tabak, R Zlotkowska, D Houthuijs, B Brunekreef, J Holikova}

See end of article for authors' affiliations

Correspondence to

Dr T Antova, National

Center of Hygiene,

Medical Ecology and

Nutrition, Blvd D Nestorov

15, Sofia 1431, Bulgaria;

t.antova@nchmen.governmen

bg

Revised version received 21 September 2002

Accepted for publication

26 October 2002

\begin{abstract}
Background: The results of studies on the effect of nutrition on respiratory diseases are inconsistent. The role of nutrition in children's respiratory health was therefore analysed within the cross sectional Central European Study on Air Pollution and Respiratory Health (CESAR).

Method: A total of 20271 children aged 7-11 were surveyed in six European countries. Respiratory health and food intake were assessed using questionnaires. Associations between four symptoms and nutritional factors were evaluated using logistic regression, controlling for area plus other potential confounders.

Results: All symptoms showed initial associations with nutritional factors. Low consumption of fish and of summer and winter fruit were the most consistent predictors. In a fully adjusted model low fish intake remained a significant independent predictor of persistent cough $(O R=1.18 ; 95 \% \mathrm{Cl} 1.04$ to 1.34), wheeze ever $(\mathrm{OR}=1.14 ; 95 \% \mathrm{Cl} 1.03$ to 1.25$)$ and current wheeze $(\mathrm{OR}=1.21 ; 95 \% \mathrm{Cl} 1.06$ to 1.39$)$ and a weaker predictor of winter cough $(\mathrm{OR}=1.10 ; 95 \% \mathrm{Cl} 0.99$ to 1.23$)$. Low summer fruit intake was a predictor of winter cough $(O R=1.40 ; 95 \% \mathrm{Cl} 1.10$ to 1.79$)$ and persistent cough $(O R=1.35$; $95 \% \mathrm{Cl} 1.01$ to 1.82). Low winter fruit intake was associated with winter cough $(\mathrm{OR}=1.28 ; 95 \% \mathrm{Cl}$ 1.09 to 1.51 ). Associations between symptoms and vegetable intake were inconsistent. Low summer intake was significantly associated with winter cough (OR=1.23; $95 \% \mathrm{Cl} 1.03$ to 1.47) but, overall, winter intake had inverse associations with both coughs. Associations between winter vegetable intake and wheeze varied considerably between countries.

Conclusion: A number of associations were found between respiratory symptoms and low intake of fish, fruit and vegetables in children. Low fish intake was the most consistent predictor of poor respiratory health. Fruit and vegetable intake showed stronger associations with cough than with wheeze.
\end{abstract}

A $\mathrm{n}$ increase in the prevalence of respiratory diseases during the last decades has pointed scientific research towards identification of risk factors contributing to this negative trend in public health. ${ }^{1}$ The wide variations in the prevalence of respiratory diseases and asthma in different countries are probably due to environmental and not genetic factors. It has been suggested that diets poor in antioxidants and minerals or with an unbalanced intake of essential fatty acids are among these potential risk factors for asthma and respiratory illness. ${ }^{23}$

The possible protective effects of fish intake on health may be due mainly to fish oil containing omega-3 polyunsaturated fatty acids (eicosapentaenoic acid (EPA) and decosahexaenoic acid (DHA)) which shunt the eicosanoid production away from the arachidonic acid pathway. Fish oil may therefore alleviate certain inflammatory respiratory diseases, ${ }^{45}$ preserve normal airway resistance, ${ }^{6}$ and modulate allergic sensitisation. ${ }^{7}$ Fruit and vegetables are rich sources of a variety of nutrients including vitamins, trace minerals, dietary fibre and biologically active compounds which have antioxidant, antibacterial, and antiviral effects and assist in detoxification of enzymes and stimulation of the immune system. ${ }^{8}$

However, epidemiological evidence linking these foods to respiratory disease has not been consistent. A few studies have observed the beneficial effect of fruit ${ }^{9}{ }^{10}$ and vegetables ${ }^{11}$ in relation to children's respiratory health, reporting a reduction in respiratory symptoms and respiratory infections and an improvement in pulmonary function. Several publications have supported these findings in adults, ${ }^{12-17}$ but others ${ }^{18}{ }^{19}$ have shown no clear associations. A potential protective role of fish in reducing the risk of asthma in childhood was reported in Australia. ${ }^{20} \mathrm{~A}$ crude association found between fish intake and asthma among Saudi Arabian children did not prove robust to controlling for other risk factors, and an increased risk of asthma with fish consumption has been reported in Japanese children. $^{21} 22$

In this paper we present data relating diet to respiratory symptoms among children participating in the Central European Study on Air pollution and Respiratory health (CESAR). Although the main focus of the CESAR study was on the relation between air pollution and children's respiratory health, some information was also gathered on diet. The resulting data set from over 20000 children allowed us to examine the role played by nutritional factors, testing the hypotheses that low intake of fresh fruit, vegetables, and fish increases the risk of respiratory disorders.

\section{METHODS}

A cross sectional multicentre study was performed in 1996 in a total of 25 areas in six Central and Eastern European countries (Bulgaria, Czech Republic, Hungary, Poland, Romania and Slovakia). Within each country, towns were selected to create a contrast in exposure to particulate air pollution. Other selection criteria were: an homogenous exposure of the subjects within each town, a sufficient number of primary school children $(>1500)$, relatively low migration rate, and comparable socioeconomic profile (towns of about 100000 citizens with comparable lifestyle characteristics, organised and accessible health services, and accessible education). A detailed selection procedure of the study areas has been described by Houthuijs et al. ${ }^{23}$

In each area about 1000 primary school children aged 7-11 were invited to participate in the study. The children were 
Table 1 Prevalence $(\%)$ of selected respiratory symptoms and frequency $(\%)$ of fish, fruit and vegetable intake in children from six Central and Eastern European countries

\begin{tabular}{|c|c|c|c|c|c|c|c|c|c|c|c|}
\hline \multirow[b]{2}{*}{ Food intake } & \multicolumn{4}{|c|}{$\begin{array}{l}\text { Prevalence (\%) of studied respiratory } \\
\text { symptoms (total for all six countries) }\end{array}$} & \multicolumn{7}{|c|}{ Frequency (\%) of fish, fruit and vegetable intake } \\
\hline & $\begin{array}{l}\text { Winter } \\
\text { cough }\end{array}$ & $\begin{array}{l}\text { Persistent } \\
\text { cough }\end{array}$ & $\begin{array}{l}\text { Wheeze } \\
\text { ever }\end{array}$ & $\begin{array}{l}\text { Current } \\
\text { wheeze }\end{array}$ & $\begin{array}{l}\text { All } \\
\text { countries }\end{array}$ & Bulgaria & $\begin{array}{l}\text { Czech } \\
\text { Republic }\end{array}$ & Hungary & Poland & Romania & Slovakia \\
\hline Fish intake & $n=19726$ & $n=19790$ & $\mathrm{n}=19218$ & $\mathrm{n}=19463$ & $n=20001$ & $n=3591$ & $n=3460$ & $n=3673$ & $n=2922$ & $n=3332$ & $\mathrm{n}=3023$ \\
\hline$\geqslant 1 /$ month & 22.1 & 13.1 & 24.3 & 9.3 & 77.3 & 74.8 & 87.3 & 63.5 & 92.6 & 60.8 & 89.3 \\
\hline$<1 /$ month & 20.3 & 13.2 & 27.9 & 10.2 & 22.7 & 25.2 & 12.7 & 36.5 & 7.4 & 39.2 & 10.7 \\
\hline Fresh fruit in summer & $n=19718$ & $n=19785$ & $\mathrm{n}=19216$ & $n=19460$ & $\mathrm{n}=19992$ & $n=3565$ & $n=3449$ & $n=3685$ & $n=2914$ & $n=3366$ & $n=3013$ \\
\hline$>4 /$ week & 20.9 & 13.0 & 24.4 & 9.4 & 74.6 & 68.4 & 83.2 & 72.0 & 77.5 & 64.9 & 83.1 \\
\hline 2-4/week & 22.9 & 12.8 & 26.6 & 9.5 & 21.8 & 24.9 & 15.6 & 24.8 & 20.3 & 28.4 & 15.5 \\
\hline$<2 /$ week & 30.8 & 15.7 & 31.1 & 11.4 & 3.7 & 6.8 & 1.2 & 3.2 & 2.2 & 6.7 & 1.3 \\
\hline Fresh fruit in winter & $n=19718$ & $\mathrm{n}=19782$ & $\mathrm{n}=19213$ & $n=19457$ & $n=19987$ & $n=3571$ & $n=3448$ & $n=3680$ & $n=2919$ & $\mathrm{n}=3354$ & $n=3015$ \\
\hline$>4 /$ week & 21.7 & 14.3 & 23.4 & 9.5 & 42.2 & 29.2 & 62.3 & 30.0 & 43.2 & 28.2 & 64.5 \\
\hline 2-4/week & 20.5 & 12.0 & 24.8 & 9.1 & 43.1 & 42.7 & 34.0 & 54.8 & 47.6 & 46.6 & 31.5 \\
\hline$<2 /$ week & 25.0 & 12.4 & 31.0 & 10.4 & 14.7 & 28.1 & 3.8 & 15.2 & 9.3 & 25.2 & 4.0 \\
\hline Fresh vegetables in summer & $n=19754$ & $n=19825$ & $\mathrm{n}=19253$ & $n=19496$ & $n=20028$ & $n=3576$ & $n=3454$ & $n=3681$ & $n=2921$ & $n=3376$ & $\mathrm{n}=3020$ \\
\hline$>4 /$ week & 21.9 & 13.5 & 26.4 & 10.2 & 58.1 & 83.8 & 55.6 & 29.4 & 61.6 & 70.9 & 48.1 \\
\hline $2-4 /$ week & 20.9 & 12.2 & 22.8 & 8.3 & 34.3 & 13.1 & 38.7 & 56.9 & 31.8 & 22.5 & 42.5 \\
\hline$<2 /$ week & 23.6 & 13.2 & 24.9 & 9.0 & 7.6 & 3.1 & 5.8 & 13.8 & 6.6 & 6.7 & 9.4 \\
\hline Fresh vegetables in winter & $n=19710$ & $\mathrm{n}=19775$ & $\mathrm{n}=19205$ & $\mathrm{n}=19450$ & $\mathrm{n}=19976$ & $n=3555$ & $n=3445$ & $n=3681$ & $n=2921$ & $n=3354$ & $n=3020$ \\
\hline$>4 /$ week & 26.2 & 16.2 & 23.9 & 11.1 & 13.0 & 9.3 & 17.3 & 7.5 & 20.3 & 12.8 & 12.4 \\
\hline 2-4/week & 21.0 & 12.8 & 22.8 & 8.7 & 45.0 & 22.3 & 54.5 & 59.3 & 51.7 & 34.5 & 48.6 \\
\hline$<2 /$ week & 21.1 & 12.3 & 27.9 & 9.7 & 42.0 & 68.4 & 28.2 & 33.2 & 28.0 & 52.7 & 39.0 \\
\hline
\end{tabular}

Table 2 Adjusted odds ratio (OR) and 95\% confidence interval (CI) of children's respiratory health associated with frequency of fish intake

\begin{tabular}{|c|c|c|c|c|c|c|c|}
\hline \multirow{2}{*}{$\begin{array}{l}\text { Outcome } \\
\text { variables of } \\
\text { respiratory health }\end{array}$} & \multirow{2}{*}{$\begin{array}{l}\text { Risk factors } \\
\text { variables } \\
\text { (categories) }\end{array}$} & \multicolumn{3}{|c|}{ Model 1} & \multicolumn{3}{|c|}{ Model 3} \\
\hline & & $\mathrm{OR}^{*}$ & $95 \% \mathrm{Cl}$ & $\mathrm{p}$ value & ORt & $95 \% \mathrm{Cl}$ & $p$ value \\
\hline \multirow[t]{2}{*}{ Winter cough } & & & $n=19725$ & & & $n=16853$ & \\
\hline & $\geqslant 1 /$ month & 1 (ref) & & & 1 (ref) & & \\
\hline \multirow[t]{2}{*}{ Persistent cough } & $<1 /$ month & 1.31 & $\begin{array}{l}1.20 \text { to } 1.44 \\
n=19789\end{array}$ & $<0.001$ & 1.10 & $\begin{array}{l}0.99 \text { to } 1.23 \\
n=16895\end{array}$ & 0.07 \\
\hline & $\geqslant 1 /$ month & 1 (ref) & & & 1 (ref) & & \\
\hline \multirow[t]{2}{*}{ Wheeze ever } & $<1 /$ month & 1.30 & $\begin{array}{l}1.16 \text { to } 1.45 \\
n=19217\end{array}$ & $<0.001$ & 1.18 & $\begin{array}{l}1.04 \text { to } 1.34 \\
n=16471\end{array}$ & 0.01 \\
\hline & $\begin{array}{l}\geqslant 1 / \text { month } \\
<1 / \text { month }\end{array}$ & $\begin{array}{l}1 \text { (ref) } \\
1.19\end{array}$ & $\begin{array}{l}1.09 \text { to } 1.29 \\
\mathrm{n}=19462\end{array}$ & $<0.001$ & $\begin{array}{l}1 \text { (ref) } \\
1.14\end{array}$ & $\begin{array}{l}1.03 \text { to } 1.25 \\
n=16648\end{array}$ & 0.01 \\
\hline Current wheeze & $\begin{array}{l}\geqslant 1 / \text { month } \\
<1 / \text { month }\end{array}$ & $\begin{array}{l}1 \text { (ref) } \\
1.24\end{array}$ & 1.10 to 1.40 & $<0.001$ & $\begin{array}{l}1 \text { (ref) } \\
1.21\end{array}$ & 1.06 to 1.39 & 0.01 \\
\hline
\end{tabular}

*OR adjusted for area, age, and sex.

†OR adjusted for all tested nutritional factors included simultaneously in the model and for area, age, sex, pets, indoor moisture, use of gas oven for heating, additional unvented gas heating, passive smoking, mother's education, father's occupation, parent's allergy, respondent and overcrowding. $\mathrm{p}=\mathrm{p}$ for trend.

recruited through their schools. Written consent was obtained from the parents of the children in January-February 1996 except in Bulgaria where consent was obtained verbally. Data on their respiratory health were gathered by questionnaires filled out by the parents of the children in February-May $1996 .{ }^{24}$

The questionnaire was composed of sections on the child's respiratory health and on lifestyle risk factors including socioeconomic status, passive smoking, indoor factors, nutrition, etc. The questions were created following the World Health Organisation questionnaire on chronic airflow limitation in children $^{25}$ and the ISAAC questionnaire on asthma in children. ${ }^{26}$

Definition of outcome respiratory variables

Four outcome variables for children's health—two for cough, two for wheeze symptoms-were defined as follows:

Winter cough: "yes" to question "Does this child usually cough during the day or at night in autumn-winter season?"
Persistent cough: "yes" to question "Did this child cough on most days for at least 3 months consecutively in the last autumn-winter season?"

Wheeze ever: "yes" to one or both of the following questions "Has this child ever had wheezing or whistling in the chest at any time in the past" and "Has this child ever had attacks of shortness of breath with wheezing?".

Current wheeze: "yes" to question "Has the child's chest sounded wheezy or whistling in the last 12 months?".

Definition of nutritional risk factors

Based on previous studies ${ }^{27} 28$ which showed that food frequency measures are accurate and useful in screening dietary surveillance, we redesigned the part of the food frequency questionnaire used in the British survey of adults ${ }^{15}$ for our study. The questions were orientated to determine the intake of fish, fruit (in summer and in winter separately), and vegetables (also in summer and winter). Parents were asked to report on the frequency of seasonal consumption of fresh food 


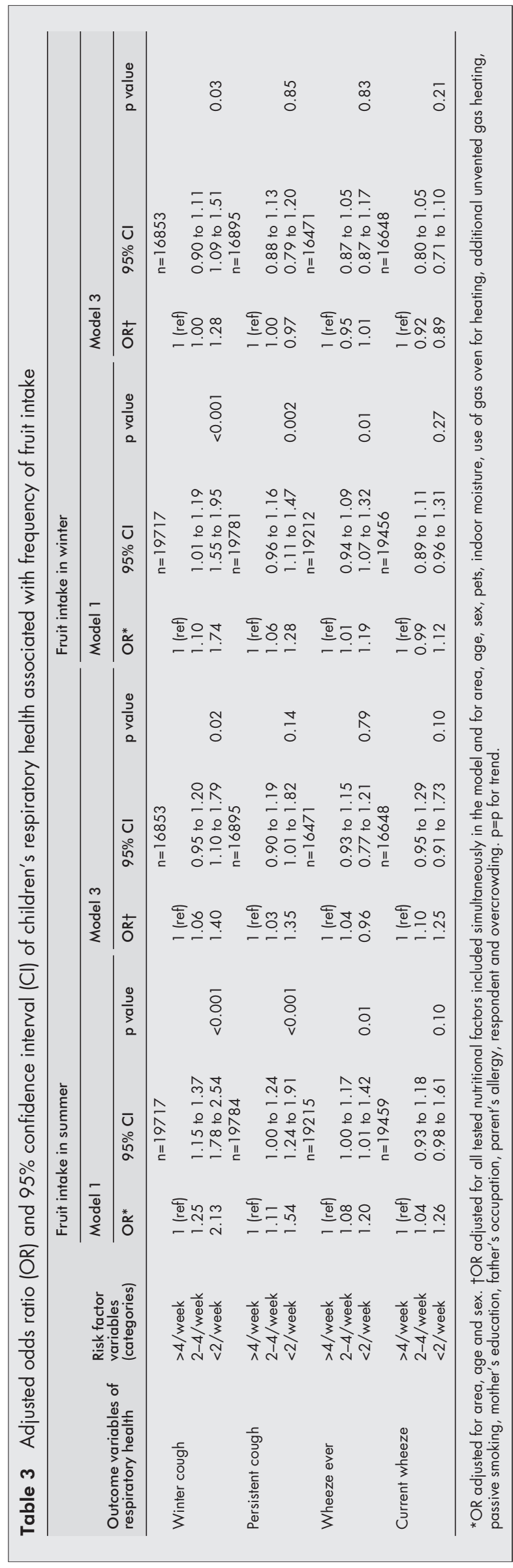

according to the usual routine in their family. For each dietary factor there were four possible responses: $>4$ times per week, 2-4 times per week, 1-4 times per month, and never or less than once per month. To avoid baseline groups of $<10 \%$ and other small categories we aggregated the groups as follows. For fruit and vegetable variables: more than 4 times per week (baseline), 2-4 times per week, and less than twice per week. For fish intake: more than once per month (baseline) and less than once per month.

\section{Statistical analysis}

The prevalence of respiratory symptoms, odds ratios (ORs) and $95 \%$ confidence intervals (CI) were determined using Stata version 6 (StataCorp, TX, USA) The ORs were estimated by logistic regression, controlling for potential confounders chosen a priori. All confounders were from the questionnaire and were included in the model as categorical variables. Tests for trend across categories of a variable were performed by including it as a linear term rather than a categorical one. This was done separately for each variable of interest-that is, while other terms were left in their categorical form.

Three statistical models were used. The first model included age, sex and area as potential confounding factors. The second model contained, in addition, the following variables: presence of pets, presence of indoor moisture, use of gas oven for heating, additional unvented gas heating, number of smokers in household $(0,1,2$ or 2+), mother's education (higher, secondary, apprenticed, primary), father's occupation (professional, clerical, skilled manual, semi/unskilled, undefined), parent's allergy (0, 1, 2 parents with allergy), respondent (person that filled out the questionnaire), and overcrowding ( $>1$ person per room). The third contained, in addition, all nutritional risk factors simultaneously in order to identify their independent associations with the outcomes.

The results from the second model were very similar to those from the fully adjusted third model, and for simplicity we report only the latter. This was true for all the nutritional factors.

The likelihood ratio test was used to test for interactions between country and nutritional factors. Where these interactions were significant the results are given separately for each country, obtained by including interaction terms in the final model.

\section{RESULTS}

A total of 33051 children were invited to participate in the study. The parents of 23731 (71.8\%) gave consent for their participation; 21743 questionnaires were returned, a response rate of $65.8 \%$. A database was created from 20271 (61.3\%) children aged 7-11 years. Children who changed address in 1995 (the year before the study, $\mathrm{n}=1194$ ) or who did not fulfil the age criteria $(n=194)$ were not included in the database. Eighty four questionnaires were not entered for various reasons, in most cases because data from all items were missing.

\section{Fish}

The "high consumption" group contained the most children, both overall and for each country (table 1). Low fish consumption was consistently associated with respiratory health (table 2). After adjusting for age, sex and area, the estimated ORs for low versus high fish intake were 1.30 for both persistent cough and winter cough, 1.24 for current wheeze, and 1.19 for wheeze ever. In the third model which contained all nutritional factors simultaneously as well as additional potential confounders, independent associations were retained with persistent cough ( $\mathrm{OR}=1.18 ; 95 \% \mathrm{CI} 1.04$ to 1.34$)$, wheeze ever $(\mathrm{OR}=1.14 ; 95 \% \mathrm{CI} 1.03$ to 1.25$)$ and current wheeze $(\mathrm{OR}=1.21 ; 95 \%$ CI 1.06 to 1.39$)$, and a weaker association with winter cough (OR=1.10; $95 \%$ CI 0.99 to 1.23$)$. 


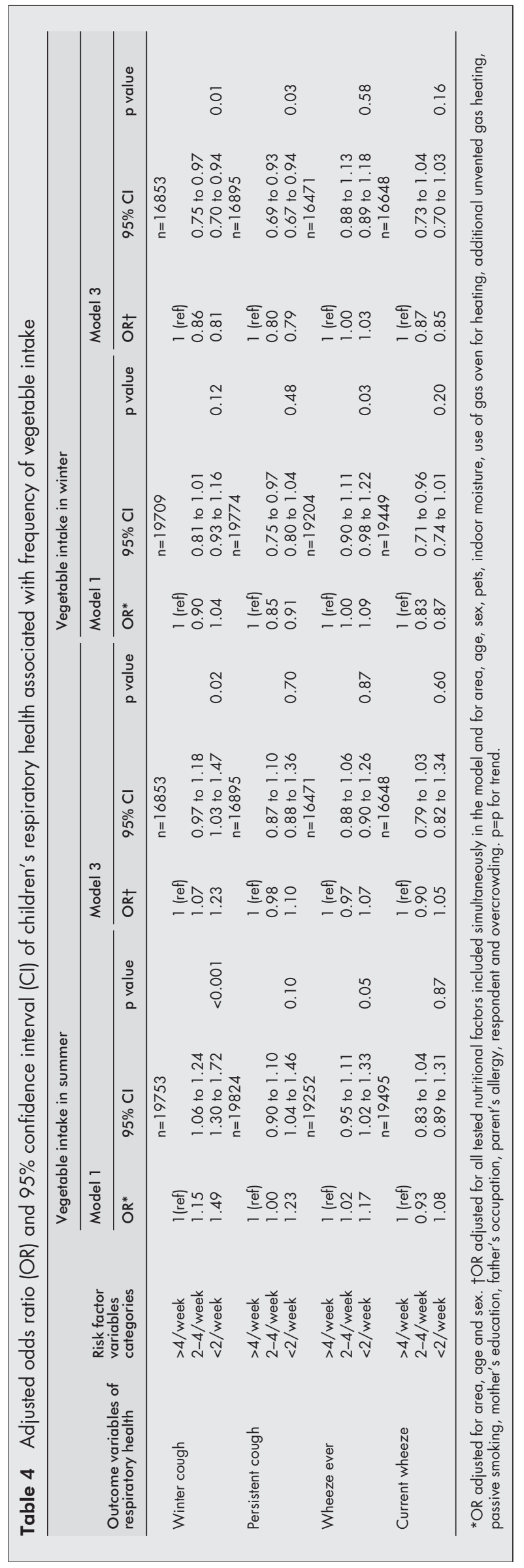

Fruit

For both summer and winter intake, the "high consumption" group contained the most children overall and the "low consumption" group contained the fewest (table 1), although for individual countries there was some variation regarding winter consumption. Winter cough was consistently associated with both summer and winter intake, with ORs for the lowest versus the highest intake groups in the final model of 1.40 (95\% CI 1.10 to 1.79 ) and 1.28 (95\% CI 1.09 to 1.51 ), respectively, and with significant trends across the intake categories (table 3). Associations with persistent cough and wheeze ever were less consistent, with trends being nonsignificant in the final model, although there remained a difference in persistent cough between the highest and lowest intake groups of summer fruit. No significant associations were seen between fruit intake and current wheeze.

\section{Vegetables}

For summer intake the "high consumption" group again contained the most children overall and the "low consumption" group contained the fewest (table 1), but the intake of winter vegetables was considerably lower. Over $40 \%$ of the children overall ate less than two portions of fresh vegetables per week in winter, ranging from $28 \%$ in Poland to $68 \%$ in Bulgaria.

Summer vegetable intake showed a consistent association with winter cough, with an OR for the lowest versus highest intake groups in the final model of 1.23 (95\% CI 1.03 to 1.47) and a significant trend across categories (table 4). Other associations with summer intake were less consistent, as were those with winter intake. After adjustment for potential confounders, low consumption of winter vegetables had an inverse association with both persistent cough and winter cough, and little association with wheeze symptoms. However, likelihood ratio tests showed highly significant interactions between country and winter vegetables for both wheeze outcomes $(p<0.001)$. Country specific associations ranged from an inverse trend for current wheeze in the Czech Republic with an OR of 0.58 (95\% CI 0.41 to 0.81 ) for the lowest versus highest intake group, to an OR for current wheeze of 2.29 (95\% CI 1.40 to 3.74 ) and for wheeze ever of 1.96 (95\% CI 1.44 to 2.67) in Bulgaria, with the remainder of the associations being non-significant or only weakly significant.

Low fish intake was therefore the most consistent predictor of poor respiratory health, having significant independent associations with both cough and wheeze symptoms. Fruit intake was associated with cough symptoms, particularly winter cough, but not with wheeze symptoms. The associations with vegetable intake were inconsistent, with a higher summer intake giving a protective effect for winter cough, while a higher winter intake of vegetables was associated with increased winter cough. Associations between wheeze symptoms and winter vegetable intake were inconsistent between countries.

\section{DISCUSSION}

This is the first attempt to analyse the role of potential nutritional risk factors in the respiratory health of children from Central and Eastern European countries. The most important finding is a clear independent association between fish intake and children's respiratory illness, particularly symptoms of wheeze and persistent cough. Hodge et al ${ }^{20}$ found that fish intake had a protective effect against childhood asthma in Australia, but otherwise there has been little consistent evidence of these associations.

Our high fish consumption category $(>1$ portion per month) is not particularly high, but the categories were formed in this way to avoid groups with very small numbers. To check that our finding was not an artefact of grouping we performed a sensitivity analysis using a three level fish variable: >2 portions/week (baseline group), 1-4 times/ 
month, and never or $<1 /$ month. Significance was greatly reduced as expected, but similar patterns of association were seen with ORs for the lowest versus highest group of 1.23 $(95 \%$ CI 1.01 to $1.51, p$ trend $=0.013)$ for persistent cough, 1.08 (95\% CI 0.92 to $1.27, \mathrm{p}$ trend $=0.058$ ) for wheeze ever, 1.13 (95\% CI 0.90 to 1.42 , p trend $=0.049)$ for current wheeze, and $1.05(95 \%$ CI 0.90 to $1.24, \mathrm{p}$ trend $=0.3)$ for winter cough (results not shown).

In accordance with some previous studies, ${ }^{910}$ our results broadly support the hypothesis of beneficial effects of fruit consumption on respiratory health, although on cough rather than wheeze symptoms. Without wishing to place too much emphasis on the least consistent results, we consider why (a) fruit consumption has stronger associations than vegetable consumption and (b) winter consumption has weaker associations-sometimes in the opposite direction-than summer consumption.

It may be that the protective effects of high fruit intake on respiratory health are genuinely much stronger than for vegetable intake. A clear beneficial association between vegetable consumption and chronic bronchitis and bronchial asthma in adults has been reported only by La Vecchia et $a l^{17}$ and a weaker beneficial trend was reported by Butland et al. ${ }^{13} \mathrm{~A}$ recent report has linked tomato intake with a reduction in respiratory infections in Sudanese children. ${ }^{11}$

The associations of higher symptom prevalence with greater winter vegetable consumption may also reflect true relationships, although we doubt this. They may be chance findings or a result of uncontrolled confounding, but we have used a wide range of individual potential confounders in our model. Another possible explanation may be that of reverse causality, given that consumption of winter vegetables was very low. In winter, when symptoms of bronchitis are most likely to be present, if fresh vegetables are given preferentially to (or sought out for) sick children, this could produce the observed results. We note that, conversely, for fruit (which is far less scarce), although associations with health are weakened they do not become inverse. Further research is needed to obtain detailed nutritional data and to explore and clarify the inconsistent associations between winter vegetable consumption and respiratory health seen across this region. Smit ${ }^{29}$ noted the inconsistency between results of previous (mainly adult) studies and recommended a meta-analysis, and this or a pooled analysis may form another approach to clarify real associations.

One of the limitations of our study is that the analysis relied on questionnaire data for frequency of food intake, but it was not possible to estimate the precise amounts and types of food, their nutrients, minerals, or total energy intake. Our exposure variables were therefore to some extent "blunt instruments", and prevented us from further distinguishing between oily and white fish, for example, or between different types of vegetables. If the "bluntness" of the nutritional variables caused misclassification we would expect this to be random, therefore biasing results towards the null. We have made great efforts to remove confounding, but inevitably some may remain. Similarly, care was taken to minimise language discrepancies in the questionnaire. A further limitation is that participants knew that the study focused on respiratory health. A wide range of potential risk factors were covered; we think serious selection or recall biases related to an association between nutrition and health are unlikely but cannot rule them out. We estimate a "real" response rate of over $65 \%$, given that some of the invited participants were ineligible for the study. Other studies quoted here had response rates ranging from 39\% to $92 \%$.

In summary, the results of our study support the hypothesis of a link between diet and respiratory health. However, estimates of effect are moderate with positive ORs ranging from about 1.10 to 1.40 . The proportion of subjects with current wheeze attributable to eating fish less than once a month, for example, is $3.7 \%$ (95\% CI 1.0 to 6.3 ), but these figures refer to common childhood symptoms with a prevalence of about $10 \%$ for current wheeze and over $20 \%$ for winter coughs. Respiratory illnesses may impact on children's schooling, affect their future health, and increase the burden both on families and on health services. Asthma in particular has been increasing in prevalence, with hypothesised links to traffic pollution and to lifestyle (which may include diet). In such a context, appropriate nutrition may have an important role to play in maintaining health and reducing the prevalence of these symptoms and their resulting burden.

\section{ACKNOWLEDGEMENTS}

The Central European Study on Air pollution and Respiratory health (CESAR) was funded by the Commission of the European Communities (CEC): Directorate General XII, Science Research and Development in the framework of the Cooperation with Third Countries and International Organisations research and technological development programme (contract number IC15-CT98-0320), and Directorate General I, External Economic Relations, in the framework of the financial and technical assistance provided to General and Eastern Europe under the Phare Multi-Country Environment programme (contract number 94-0472).

....................

Authors' affiliations

T Antova, B Nikiforov, B Boeva, National Center of Hygiene, Medical Ecology and Nutrition, Sofia, Bulgaria

S Pattenden, G S Leonardi, T Fletcher, London School of Hygiene and Tropical Medicine, London, UK

P Rudnai, National Institute of Environmental Health, Budapest, Hungary H Slachtova, Regional Institute of Hygiene, Ostrava, Czech Republic

C Tabak, D Houthuijs, National Institute of Public Health and the

Environment (RIVM), Bilthoven, The Netherlands

R Zlotkowska, Institute of Occupational Medicine and Environmental Health, Sosnowiec, Poland

B Brunekreef, Institute for Risk Assessment Sciences, Utrecht University, Utrecht, The Netherlands

J Holikova, Institute of Public Health, Banska Bystrica, Slovak Republic

\section{REFERENCES}

1 Weiss, ST. Diet as a risk factor for asthma. Ciba Clinical Symposia 1997; 206:244-57.

2 Peat, JK, Gray S, Woolcock AJ. The epidemiology of asthma. Curr Opin Pulm Med 1995;1:9-15.

3 Dry J, Vincent D. Effect of a fish oil diet on asthma: results of a 1-year double blind study. Int Arch Allergy Immunol 1991;95:156-7.

4 Maple C, McLaren M, Bancroft A, et al. Dietary supplementation with omega 3 and omega 6 fatty acids reduces induced white blood cell aggregation in healthy voluntaries. Prostaglandins Leukot Essent Fatty Acids 1998:58:365-8.

5 Powell WS, Gravel S, Gravelle F. Formation of a 5-oxo metabolite of $5,8,11,14,17$-eicosapentanoic acid and its effects on human neutrophils and eosinophils. J Lipid Res 1995;36:2590-8.

6 Villani F, Comazzi R, De Maria P, et al. Effect of dietary supplementation with polyunsaturated fatty acids on bronchial hyperreactivity in subjects with seasonal asthma. Respiration 1998;65:265-9

7 Black PN, Sharpe S. Dietary fat and asthma: is there a connection? Eur Respir J 1997;10:6-12.

8 Lampe JW. Health effect of vegetables and fruit: assessing mechanisms of action in human experimental studies. Am J Clin Nutr 1999;70(Suppl):475-90.

9 Cook DG, Carey IM, Whincup PH, et al. Effect of fresh fruit consumption on lung function and wheeze in children. Thorax 1997;52:628-33.

10 Forastiere F, Pistelli R, Sestini $P$, et al. Consumption of fresh fruit rich in vitamin $C$ and wheezing symptoms in children. Thorax 2000;55:283-8. 11 Fawzi W, Herrera MG, Nestel P. Tomato intake in relation to mortality and morbidity among Sudaneze children. J Nutr 2000;130:2537-42.

12 Miedema I, Feshkens EJM, Heederik D, et al. Dietary determinants of long-term incidence of chronic non-specific lung diseases: the Zuthen study. Am J Epidemiol 1993;138:37-45.

13 Butland BK, Strachan DP, Anderson HR. Fresh fruit intake and asthma symptoms in young British adults: confounding or effect modification by smoking? Eur Respir J 1999:13:744-50.

14 Tabak C, Smit HA, Rasanen L, et al. Dietary factors and pulmonary function: a cross sectional study in middle aged men from, three European countries. Thorax 1999;54:1021-6.

15 Strachan DP, Cox BD, Erzinclioglu SW, et al. Ventilatory function and winter fresh fruit consumption in a random sample of British adults. Thorax 1991;46:624-9. 
16 Carey IM, Strachan DP, Cook DG. Effect of changes in fresh fruit consumption on ventilatory function in healthy British adults. Am J Respir Crit Care Med 1998;158:728-33

17 La Vecchia C, Decarli A, Pagano R. Vegetable consumption and risk of chronic disease. Epidemiology 1998:9:208-10.

18 Morabia A, Sorenson A, Kumanyika SK, et al. Vitamin A, cigarette smoking, and airway obstruction. Am Rev Respir Dis 1989;140:1312-6.

19 Troisi RJ, Willen WC, Weiss ST, et al. A prospective study of diet and adult-onset asthma. Am J Respir Crit Care Med 1995:151:1401-8.

20 Hodge L, Salome CM, Peat JK, et al. Consumption of oily fish and childhood asthma risk. Med J Aust 1996;164:137-40.

21 Hijazi N, Abalkhail B, Seaton A. Diet and childhood asthma in a society in transition: a study in urban and rural Saudi Arabia. Thorax 2000;55:775-9

22 Tekemura $Y$, Sakurai $Y$, Satoshi $H$, et al. The relationship between fish intake and the prevalence of asthma: the Tokorozawa Childhood Asthma and Pollinosis Study. Prevent Med 2002;34:221-5.

23 Houthuijs D, Breugelmans B, Hoek G, et al. PM $\mathrm{PM}_{10}$ and $\mathrm{PM}_{2.5}$ concentrations in Central and Easern Europe: results from the Cesar study. Atmos Environ 2001;35:2757-71.
24 Leonardi GS, Houthuiis D, Nikiforov B, et al. Respiratory symptoms, bronchitis and asthma in children of Central and Eastern Europe. Eur Respir J 2003 (in press).

25 Florey CV, Leeder SRE. Methods of cohort studies of chronic airflow limitation. WHO Regional Publications, European Series No 12, Copenhagen, 1982.

26 Asher MI, Keil U, Anderson HR, et al. International study of asthma and allergies in childhood (ISAAC): rationale and methods. Eur Respir J 1995;8:483-91.

27 Byers T, Trieber F, Gunter E, et al. The accuracy of parental reports of their children's intake of fruits and vegetables: validation of the food-frequency questionnaire with serum levels of carotenoids and vitamins C, A and E. Epidemiology 1993;4:350-5.

28 Hu FB, Rimm E, Smith-Warner SA, et al. Reproducibility and validity of dietary patterns assessed with a food-frequency questionnaire. Am J Clin Nutr 1999;69:243-9.

29 Smit HA. Chronic obstructive pulmonary disease, asthma and protective effects of food intake: from hypothesis to evidence? Respir Res $2001 ; 2: 261-4$

\section{LUNG ALERT}

\section{Pulmonary artery catheters are not routinely indicated during and after surgery}

A Sandham JD, Hull RD, Brant RF, et al for the Canadian Critical Care Clinical Trials Group. A randomized, controlled trial of the use of pulmonary-artery catheters in high-risk surgical patients. N Engl J Med 2003;348:5-14

D ecent observational studies suggest that the use of pulmonary artery catheters to guide treatment is associated with increased mortality. Outcomes have been confounded by the I severity of the underlying illness. This multicentre, randomised, controlled clinical trial involving blinded assessment of outcomes compared treatment guided by a pulmonary artery catheter with standard treatment (not guided by a pulmonary artery catheter) in 1994 at risk elderly patients (American Society of Anaesthesiologists class III and IV risk) undergoing surgery followed by a stay in the intensive care unit (ICU). Patients were aged $\geqslant 60$ years and were scheduled for urgent or elective major abdominal, thoracic, vascular, or hip fracture surgery. There was no difference between the two groups in rate of in-hospital mortality, length of hospital stay (median 10.0 days for both), or survival at 6 or 12 months. However, there was a higher rate of acute pulmonary embolism in the catheter group $(8 v 0, \mathrm{p}=0.004)$.

The study showed that, in this group of patients, medical management directed by pulmonary artery catheters had no advantage over standard treatment. Whether the results of this study extend to patients other than those at high risk is not at present known.

T A R Seemungal 